Article

\title{
Adaptive strategies of Rice Leaf Roller, Cnaphalocrocis medi- nalis in response to different rearing temperatures
}

\author{
Weixiang $\mathrm{Lv}^{1,2}$, Xingfu Jiang ${ }^{1}$, Xiujie Chen ${ }^{1}$, Yunxia Cheng ${ }^{1}$, Jixing Xia ${ }^{1}$ and Lei Zhang ${ }^{1 *}$ \\ 1 State Key Laboratory for Biology of Plant Diseases and Insect Pests, Institute of Plant Protection, Chinese \\ Academy of Agricultural Sciences, Beijing, 100193, China; lvwx@cwnu.edu.cn (W.X.L.); xfiang@ippcaas.cn \\ (X.F.J.); 1308363945@qq.com(X.J.C.); yxcheng@ippcaas.cn (Y.X.C.);158601460@qq.com(J.X.X.); \\ 2 Key Laboratory of Southwest China Wildlife Resources Conservation, China West Normal University, \\ Nanchong, China \\ * Correspondence: leizhang@ippcaas.cn (L.Z.)
}

Simple Summary: Temperature directly affects the immature development, adult reproduction and subsequent migratory behavior for migratory insects. However, the adaptive strategies how to cope with stressful temperatures throughout their life cycle in some migratory insects are not well understood. In this study, we investigated the effects of rearing temperatures in the immature stage on immature development, adult reproduction and flight performance of Cnaphalocrocis medinalis, one major migratory pest feeding on rice. Our data suggest that $C$. medinalis may use different adaptive strategies to buffer the impacts of unsuitable temperatures. C. medinalis at high rearing temperatures can accelerate maturation development and invest more energy in migration to improve survival at the costs of delayed reproduction processes and reduced reproduction output. However, C. medinalis at low rearing temperatures accelerates reproduction processes and stimulates adult reproduction but delays maturation development.

\begin{abstract}
Understanding how species that follow different life-history strategies respond to stressful temperature can be essential to efficient treatments against agricultural pests. Here we focus on how the development and reproduction of $C$. medinalis is influenced by exposure to different rearing temperatures in the immature stage. We found that low $\left(18\right.$ or $\left.22^{\circ} \mathrm{C}\right)$ or high $(30$ and $34^{\circ} \mathrm{C}$ ) rearing temperatures negatively affected the immature development and flight performance compared to the normal temperature $26^{\circ} \mathrm{C}$, with higher larval and pupal mortality, lower pupation and eclosion rates and shorter flight duration and distance. Low rearing temperatures significantly slowed down the immature process, but accelerated adult reproduction. However, high rearing temperatures had the opposite impacts. Interestingly, the flight of adults with un-mature rearing low temperatures $\left(18\right.$ and $\left.22{ }^{\circ} \mathrm{C}\right)$ significantly decreased their lifetime fecundity and mating frequency, but increased pre-oviposition period of females compared to the control; On contrast, high rearing temperatures $\left(30\right.$ and $34{ }^{\circ} \mathrm{C}$ ) significantly accelerated onset of oviposition and enhanced synchrony of spawning. These results indicate high rearing temperatures in the immature stage are more likely to trigger the onset of migration, but low rearing temperatures induces adults to have a greater resident propensity with stronger reproductive ability.
\end{abstract}

Keywords: Cnaphalocrocis medinalis; rearing temperatures; development; reproduction; flight performance

\section{Introduction}

Temperature is the major determinant factor influencing the organismal performance and the response to biotic and abiotic stressors as well as the biological processes of insects [1-4]. Previous studies have widely reported variations of development rates, survival rates, fecundity, longevity and other life-history characteristics in response to rearing temperatures in Lepidoptera and other insect species [5-7]. Development and reproduction of insects are largely dependent on environmental temperatures, with op- 
timal environmental temperatures having a positive effect. On contrast, high or low temperatures negatively impact reproduction and population growth [8-10]. Jiang et al. [11] reported that the development, reproduction and longevity of Mythimna separata (Walker) exposed to high temperatures (above $30^{\circ} \mathrm{C}$ ) were restrained, as demonstrated in Sitophilus granaries (L.) and other insect species [12-13]. Low temperatures reduced the development and fecundity in Autographa gamma (L.) [14] and delayed the pre-calling period in M. separata (Walker) [15]. To ensure survival and reproduction, insects adjusted their development and physiology to deal with extreme environmental conditions throughout their life cycle [16]. Ma et al. [17] revealed that trade-off between reproductive traits and response to environmental impacts was an important part of the life history strategy in insects, which impaired the damage of extreme temperatures on the insects.

Seasonal migrations like many bird species occur on a large scale and frequently in many migratory insects [18]. Long-distance migration behavior has been an important adaptive life history strategy for population maintenance and evolution of migratory insects [19-20], which allows migratory species to leave deteriorating habitats and seek for new breeding habitats [21-22]. Energetic investments in migration and flight organs are costly for limited internal resources, which may reduce energy investment in reproduction at the result of producing fewer offspring [23-24]. Resource trade-off between reproduction and flight associated characters during migration is common in most insects, such as Aphis glycines (Matsumura), Spodoptera exempta (Walker) and crickets [2527], and this phenomenon was termed as the oogenesis-flight syndrome [28]. Zhang et al. [24] reported that migration-mediated reproductive costs were not absolutely negative, but instead depended on age, duration and frequency of the moth's initial flight. However, the trade-off between migration and reproduction under different rearing temperatures remains unknown in most long-distance migrants.

The rice leaf roller, Cnaphalocrocis medinalis (L.) (Lepidoptera: Pyralidae), is one predominant herbivorous pest in the rice ecosystems, which has caused serious economic losses in Asia, Australia and East Africa, especially in China [29-30]. In China, C. medinalis has been confirmed that they cannot overwinter in the north area of $30^{\circ} \mathrm{N}$ [31]. It is most likely that migration in C. medinalis is an important adaption to seasonal and regional variations, similar to M. separata [32-33]. Most studies have been conducted on long-term monitoring and seasonal migratory mechanism of $C$. medinalis adults [30, 3435]. However, it remains unknown how C. medinalis copes with temperature variations throughout their life cycle and temperature stress to affect the trade-off between migration and reproduction. To gain insight into these questions above, we investigated the larval development, adult reproduction and flight capacity at different rearing temperatures in laboratory conditions. These results revealed C. medinalis larvae and adults can deal with ambient temperature stress to ensure survival and reproduction. This study expands our knowledge of the population adaptation strategy of C. medinalis with complex ambient environments and contributes to the pest management.

\section{Materials and Methods}

\subsection{Insect rearing}

Rice leaf roller pupae were collected from rice fields in Changde, Hunan Province, China, and then the populations were reared for obtaining eggs under laboratory conditions $\left(26 \pm 1^{\circ} \mathrm{C}, 85 \pm 5 \%\right.$ relative humidity $(\mathrm{RH})$ and a photoperiod of 16L: $\left.8 \mathrm{D}\right)$. Larvae in this experiment were reared with fresh corn seedlings $7-9 \mathrm{~cm}$ in height in the glass bottles $(9 \mathrm{~cm} \times 13 \mathrm{~cm}$, diameter $\times$ height) until pupation. After pupation, the pupae were transferred from leaves in glass bottles with moist cotton wool on the bottom to optimize conditions. After emergence, each pair of newly female and male moth was immediately transferred into new cylindrical plastic cages $(10 \mathrm{~cm} \times 20 \mathrm{~cm}$, diameter $\times$ height $)$ and fed with fresh $10 \%$ honey solution (v/v) daily until the death of adults [24].

\subsection{Temperature treatments}


To investigate the influence of rearing temperature on development of immature stage (from egg to pupae stage), five temperature treatments were selected in this experiment, including 18,22, 26, 30 and $34^{\circ} \mathrm{C}$ (encountered by $\mathrm{C}$. medinalis in the field) under which $C$. medinalis were reared during immature stage. The eggs and subsequent hatched larvae were reared at the five constant rearing temperatures under a photoperiod of 16L: 8D and $85 \pm 5 \%$ humidity until the eclosion of moths. Larvae were reared in culture plates (1 larval/well) and fed with maize seedlings at $85 \pm 5 \%$ relative humidity (RH) with a 16:8 h light: dark.

\subsection{Larval development of $C$. medinalis}

For the each temperature treatment, eggs laid at the same time were gently collected and individually placed in every well of 6-well plates to observe hatching every day. Subsequently, all the hatched larvae were reared on fresh corn leaves until pupation, and the instar stage and number of surviving larvae were examined and recorded daily. Egg-larval period included the duration from egg hatching to pupation, and pupal period was the duration between pupation to adult emergence. Subsequently, all the hatched larvae were reared on fresh corn leaves until pupation, and the instar stage and number of surviving larvae were examined and recorded daily. The individuals in each temperature treatment were divided into 3 replicates to count the larval and pupal mortality rate. Similarly, pupation and eclosion rates were calculated based on the number of pupae and emerging adults. The period of synchronized eclosion was defined as the number of days between a pupa's period of eclosion and the minimal period of eclosion among all pupae in the same treatment. It was used to measure the synchronization of adult emergence. The lower value of the period of eclosion represented the synchronized eclosion. The sex ratio was used to calculate the proportion of female and male adults [36].

\subsection{Reproductive parameter determination}

This experiment was designed to detect the influence of larval rearing temperatures on adult reproduction. After emergence, females and males from five temperature treatments were immediately paired (one male and one female) at each treatment and fed in cylindrical plastic cages $(10 \mathrm{~cm} \times 20 \mathrm{~cm}$, diameter $\times$ height $)$ at $26 \pm 1^{\circ} \mathrm{C}, 85 \%-95 \% \mathrm{RH}$ with a photoperiod of $14 \mathrm{~L}: 10 \mathrm{D}$. The oviposition of the adults was observed and recorded daily until death. The reproductive parameters were measured based on previous studies [3738], which were used to evaluate the variations in response to different temperatures. The pre-oviposition period (POP) was an important parameter to describe the duration from newly emergence to the first oviposition of adults. The period of first oviposition (PFO) was used to compute and evaluate the synchronization of first oviposition, which defined as the period from a female's POP to the minimal POP in a treatment. The lower PFO value showed the more synchronized initial oviposition [39]. After female death, the number of spermatophores was observed, and the mating frequency and mating rate were calculated [24]. Data were excluded from the analyses if either male or female escaped during the experiment. The experiments were terminated when all of the males and females died.

\subsection{Flight treatment and capacity assessments}

The measurement of flight performance was conducted with a 48-channel flight mill system, which automatically recorded the flight parameters (flight duration, flight distance and average flight velocity) [24, 40].

All the newly emerged moths including one-day-old females and males were anesthetized with ether, and the scales on the junction between the metathorax and abdomen were brushed away. A short hollow-plastic tether was glued to the dorsal surface of the metathorax using 502 super adhesives (Beijing Chemical Co.) and the adults were provided with $10 \%$ honey solution (v/v) before tethered flight. All tethered moths were tested for 6-h flight (23:00-05:00) on flight mills under dark condition at $26 \pm 1^{\circ} \mathrm{C}$ and 
$80 \%-85 \% \mathrm{RH}[24,35,36]$. The number of replicates of five immature temperature treatments $\left(18,22,26,30\right.$ and $\left.34^{\circ} \mathrm{C}\right)$ were 14, 28, 19, 14 and 26 females, and 14, 30, 28, 15, 30 males, respectively. After tethered flight test, females and males were immediately paired and fed in cylindrical plastic cages under laboratory conditions. The reproductive parameters mentioned above were observed and recorded daily until death. The moths which were not tethered flight were used as the control.

\subsection{Data analysis}

All larval development parameters, flight capacity and reproductive parameters of adults were analyzed using one-way analysis of variance (ANOVA) followed by Tukey's honestly significant difference (HSD) test $(\mathrm{P}<0.05)$ or independent samples $\mathrm{t}$-tests $(\mathrm{P}<$ 0.05). Flight capacity was also analyzed by a two-way ANOVA with sex (two levels) and rear temperature (five levels). To compare the impact of flight (flying vs. non-flying) and rear temperatures $\left(18,22,26,30\right.$ and $\left.34^{\circ} \mathrm{C}\right)$ on adult reproduction, two-way analysis of variance (ANOVA) was also used. All statistical analyses were performed with SPSS software (version 18.0; SPSS, Chicago, IL, USA).

\section{Results}

\subsection{Development of C. medinalis exposed to different un-mature rearing temperatures}

Rearing temperatures had a significant influence on $C$. medinalis from egg to larval period $\left(F_{4,1132}=3246.68, P<0.01\right)$ and pupal period $\left(F_{4,1132}=771.84, P<0.01\right)$. Low temperatures $\left(18\right.$ and $22{ }^{\circ} \mathrm{C}$ ) significantly extended the larval period and pupal period compared to the treatments of 26,30 and $34^{\circ} \mathrm{C}$ at the result of significantly delaying larval and pupal development under these temperatures. However, the mostly significant effects on larval period and pupal periods were found in the C. medinalis reared at $30{ }^{\circ} \mathrm{C}$ compared with other treatments (Table 1). Below or above $26{ }^{\circ} \mathrm{C}$ increased the mortality rate of larvae and pupae, and reduced the pupation rate, eclosion rate and sex ratio, although there were no significant differences (Table 1$)(P>0.05)$. However, $C$. medinalis pupae exposed to low temperatures $\left(18\right.$ and $\left.22^{\circ} \mathrm{C}\right)$ had a significantly higher period of synchronized eclosion than those at 26,30 and $34{ }^{\circ} \mathrm{C}\left(F_{4,1132}=64.21, P<0.01\right.$, Table 1$)$.

\subsection{Flight capacity of $C$. medinalis emergenced from different un-mature rearing temperatures}

Rearing temperatures had significant effects on the flight duration and flight distance. However, the sex and interaction between rearing temperatures and sex had no effect on the flight duration and flight distance (Table 2,3). There were no significant differences in average velocity of females and males (Table 2, 3).

Females at $26^{\circ} \mathrm{C}$ had the longest flight duration and flight distance, which were significantly higher than those at $30{ }^{\circ} \mathrm{C}$ (flight duration: $F_{4,110}=2.83, P=0.03$; flight distance: $F_{4,110}=3.14, P=0.02$, Table 3$)$. Similarly, high rearing temperatures $\left(30\right.$ and $\left.34{ }^{\circ} \mathrm{C}\right)$ significantly decreased flight duration and flight distance of males compared to the moths exposed to $26^{\circ} \mathrm{C}$ (flight duration: $F_{4,105}=3.98, P=0.03$; flight distance: $F_{4,105}=3.17, P$ $=0.02$, Table 3 ).

Comparisons of flight capacity between females and males showed that females exposed to $18{ }^{\circ} \mathrm{C}$ had a lower flight duration, flight distance and average velocity than males; in contrast, their flight duration, flight distance and average velocity exceeded males in the above $18{ }^{\circ} \mathrm{C}$ treatments, especially the $34{ }^{\circ} \mathrm{C}$, significant decrease was observed in flight duration $\left(t_{53}=2.51, P=0.02\right)$, indicating that females might have greater flight potential than males at above $18^{\circ} \mathrm{C}$ (Table 3).

\subsection{Influence of un-mature rearing temperature and flight on reproduction}

Rearing temperature and the interaction between flight and rearing temperature significantly affected the POP (Rearing temperature: $F_{4,239}=3.21, P=0.01$; Flight * rearing temperature: $F_{4,239}=5.88, P<0.01$, Table 4$)$. 
The PFO was significantly influenced by the flight and the interaction between flight and rearing temperature (Flight: $F_{1,239}=7.44, P<0.01$; Flight ${ }^{*}$ rearing temperature: $F_{4,239}=$ 5.50, $P<0.01$, Table 4). Flight, rearing temperature and their interaction had significant effects on the lifetime fecundity, mating frequency and female longevity (Table 4). The oviposition period was significantly affected by flight and rearing temperature, but not by their interaction (Flight: $F_{1,239}=5.23, P=0.02$; Rearing temperature: $F_{4,239}=5.88, P<$ 0.01 , Table 4). Only flight had significant effects on the mating rate (Flight: $F_{1,239}=4.48, P=$ 0.04 , Table 4).

Rearing temperature had a significant effect on the POP of females between the two groups (Flying group: $F_{4,99}=2.49, P=0.05$; Nonflying group: $F_{4,140}=6.13, P<0.01$, Fig 1 ). Nonflying females at 18 and $22^{\circ} \mathrm{C}$ had significantly shorter POPs than the moths at $26^{\circ} \mathrm{C}$. However, in the flying groups, females at $18^{\circ} \mathrm{C}$ had the longest POP in all temperature treatments, which was significantly longer than the moths at $30{ }^{\circ} \mathrm{C}$ (Fig 1). In the nonflying groups, high rearing temperatures $\left(30\right.$ and $34{ }^{\circ} \mathrm{C}$ ) increased the PFOs of females compared to the treatments of 18,22 and $26^{\circ} \mathrm{C}$, but there were no significant differences $\left(F_{4,140}=2.42, P>0.05\right.$, Fig 2$)$. However, in the flying group, high rearing temperatures (30 and $34{ }^{\circ} \mathrm{C}$ ) significantly reduced the $\mathrm{PFO}$ of flying females compared to the treatment of $22{ }^{\circ} \mathrm{C}\left(F_{4,99}=4.40, P<0.01\right)$, causing a better synchronization of first oviposition under these high treatments (Fig 2). There were significant differences in lifetime fecundity of females between the two groups treated by different rearing temperatures (Flying group: $F_{4,99}=3.48, P=0.01$; Nonflying group: $F_{4,140}=9.23, P<0.01$, Table 5). Females at 18 and 22 ${ }^{\circ} \mathrm{C}$ laid more eggs than the moths at 26,30 and $34^{\circ} \mathrm{C}$ in the nonflying group. Similarly, flight-induced lifetime fecundity of females at $18^{\circ} \mathrm{C}$ was significantly higher than that in the $34{ }^{\circ} \mathrm{C}$ treatment (Table 5).

Rearing temperature significantly affected the mating frequency of females in the nonflying group $\left(F_{4,140}=2.21, P<0.01\right)$. Females at $18^{\circ} \mathrm{C}$ had the greatest mating frequency, which was higher than those in the 26,30 and $34{ }^{\circ} \mathrm{C}$ treatments of the nonflying group. But there was no significant difference in mating frequency of females in the flying group $\left(F_{4,99}=0.53, P>0.05\right.$, Table 5). Significant differences were found for the female longevity between the two groups treated by different rearing temperatures (Flying group: $F_{4,99}=7.40, P=0.01$; Nonflying group: $F_{4,140}=8.48, P<0.01$, Table 5$)$. High rearing temperatures $\left(30\right.$ and $34^{\circ} \mathrm{C}$ ) significantly decreased the female longevity compared to the treatments of 18 and $26^{\circ} \mathrm{C}$ in the nonflying group. The female longevity at $34^{\circ} \mathrm{C}$ was also significantly shorter than the moths at $18^{\circ} \mathrm{C}$ in the flying group (Table 5). Likewise, the oviposition period $\left(F_{4,140}=8.48, P<0.01\right)$ and mating rate $\left(F_{4,140}=2.76, P=0.03\right)$ of moths at 30 and $34{ }^{\circ} \mathrm{C}$ were significantly lower than those in the 18 and $22{ }^{\circ} \mathrm{C}$ treatments of the nonflying group (Table 5). In the flying group, the greatest oviposition period occurred in females exposed to $18{ }^{\circ} \mathrm{C}$, which was significantly higher than that in the 22,30 and $34{ }^{\circ} \mathrm{C}$ treatments $\left(F_{4,99}=6.79, P<0.01\right.$, Table 5$)$. However, rearing temperature had no significant differences in mating rate of flying moths $\left(F_{4,99}=0.53, P>0.05\right.$, Table 5$)$.

Flight significantly reduced the POPs of females treated with 26,30 and $34{ }^{\circ} \mathrm{C}$ compared to the controls (the nonflying moths) at each rearing temperature $\left(26^{\circ} \mathrm{C}: t_{56}=-2.06\right.$, $\left.P=0.04 ; 30{ }^{\circ} \mathrm{C}: t_{34}=-3.34, P<0.01 ; 34{ }^{\circ} \mathrm{C}: t_{45}=-3.49, P<0.01\right)$, resulting in beginning to oviposit significantly earlier under these temperatures. However, flying females at $18{ }^{\circ} \mathrm{C}$ showed a significant delay in spawning $\left(t_{44}=2.98, P<0.01\right.$, Fig 1$)$. The PFOs of moths at 30 and $34{ }^{\circ} \mathrm{C}$ were significantly decreased by the flight compared to the controls at the same temperature $\left(30^{\circ} \mathrm{C}: t_{34}=-4.64, P<0.01 ; 34{ }^{\circ} \mathrm{C}: t_{45}=-3.49, P=0.01\right)$, indicating the synchronized oviposition of flying females exposed to high temperatures was better than the nonflying moths. Furthermore, flying females at 18 and $22{ }^{\circ} \mathrm{C}$ had a higher PFO than the nonflying females, but the difference was not significant (Fig 2). Flight also significantly decreased the lifetime fecundity $\left(18{ }^{\circ} \mathrm{C}: t_{44}=-3.73, P<0.01 ; 22{ }^{\circ} \mathrm{C}: t_{65}=-4.94, P<\right.$ $0.01)$ and mating frequency $\left(18^{\circ} \mathrm{C}: t_{44}=-3.25, P<0.01 ; 22{ }^{\circ} \mathrm{C}: t_{65}=-2.38, P=0.02\right.$, Table 5$)$ of females exposed to 18 and $22{ }^{\circ} \mathrm{C}$ than the nonflying moths. Similarly, flying females at 22 and $26{ }^{\circ} \mathrm{C}$ had significantly shorter longevities than the nonflying moths $\left(22^{\circ} \mathrm{C}: t_{65}=-3.41\right.$, 
$P<0.01 ; 26{ }^{\circ} \mathrm{C}: t_{56}=-2.99, P<0.01$, Table 5). Compared to the nonflying moths, the oviposition period of females at $22{ }^{\circ} \mathrm{C}$ was significantly shortened by the flight $\left(t_{56}=-3.85, P<\right.$ 0.01 , Table 5). Similarly, flight significantly decreased the mating rate of females at $18{ }^{\circ} \mathrm{C}$ compared to the nonflying moths $\left(t_{44}=-2.464, P=0.018\right.$, Table 5).

\subsection{Tables and Figures}

Table 1 Larval development of C. medinalis under different rearing temperatures.

\begin{tabular}{|c|c|c|c|c|c|}
\hline \multirow[t]{2}{*}{ Development parameter } & \multicolumn{5}{|c|}{ Rearing temperatures } \\
\hline & $18^{\circ} \mathrm{C}$ & $22{ }^{\circ} \mathrm{C}$ & $26^{\circ} \mathrm{C}$ & $30^{\circ} \mathrm{C}$ & $34^{\circ} \mathrm{C}$ \\
\hline Egg-larval period (d) & $53.80 \pm 0.39 \mathrm{a}$ & $30.59 \pm 0.23 b$ & $23.76 \pm 0.08 \mathrm{c}$ & $21.76 \pm 0.17 \mathrm{~d}$ & $23.25 \pm 0.14 \mathrm{c}$ \\
\hline Pupal period (d) & $17.83 \pm 0.31 \mathrm{a}$ & $8.87 \pm 0.19 b$ & $5.78 \pm 0.09 \mathrm{c}$ & $4.41 \pm 0.11 \mathrm{~d}$ & $4.99 \pm 0.10 \mathrm{~d}$ \\
\hline Larval mortality rate $(\%)$ & $74.00 \pm 10.51 \mathrm{a}$ & $49.35 \pm 12.52 \mathrm{a}$ & $46.00 \pm 25.14 \mathrm{a}$ & $59.72 \pm 8.30 \mathrm{a}$ & $53.05 \pm 18.49 \mathrm{a}$ \\
\hline Pupal mortality rate $(\%)$ & $36.45 \pm 23.86 \mathrm{a}$ & $25.62 \pm 8.71 \mathrm{a}$ & $18.85 \pm 3.45 \mathrm{a}$ & $27.06 \pm 11.67 \mathrm{a}$ & $27.70 \pm 5.04 \mathrm{a}$ \\
\hline Pupation rate $(\%)$ & $35.14 \pm 25.47 \mathrm{a}$ & $50.65 \pm 12.52 \mathrm{a}$ & $54.00 \pm 25.14 \mathrm{a}$ & $40.28 \pm 8.30 \mathrm{a}$ & $46.95 \pm 18.49 \mathrm{a}$ \\
\hline Eclosion rate $(\%)$ & $71.34 \pm 8.15 \mathrm{a}$ & $59.94 \pm 23.97 \mathrm{a}$ & $76.64 \pm 3.98 \mathrm{a}$ & $70.82 \pm 13.31 \mathrm{a}$ & $68.61 \pm 6.28 \mathrm{a}$ \\
\hline Period of synchronized eclosion (d) & $9.40 \pm 0.48 \mathrm{a}$ & $5.66 \pm 0.24 \mathrm{~b}$ & $4.08 \pm 0.13 \mathrm{c}$ & $4.29 \pm 0.20 \mathrm{c}$ & $4.61 \pm 0.17 \mathrm{c}$ \\
\hline Sex ratio $\left(q:{ }^{\lambda}\right)$ & $1.06 \pm 0.40 \mathrm{a}$ & $1.28 \pm 0.31 \mathrm{a}$ & $1.36 \pm 0.35 \mathrm{a}$ & $1.11 \pm 0.71 \mathrm{a}$ & $1.24 \pm 0.78 \mathrm{a}$ \\
\hline
\end{tabular}

Means with the different letters in the same row represent significant differences at the $5 \%$ level by Tukey's HSD test. Sample sizes of 18, 22, 26, 30 and $34{ }^{\circ} \mathrm{C}$ treatments are 153 , 356, 443, 217 and 318, respectively.

Table 2 Results of two-way ANOVA analysis of rear temperature and sex on flight capacity of $C$. medinalis.

\begin{tabular}{|c|c|c|c|c|c|}
\hline Parameters & Source & Df & MS & $\boldsymbol{F}$ & $P$ \\
\hline \multirow[t]{5}{*}{ Flight duration (h) } & Rear temperature & 4 & 17.56 & 5.12 & $<$ \\
\hline & & & & & 0.001 \\
\hline & Sex & 1 & 2.88 & 0.84 & 0.360 \\
\hline & Rear temperature $\times$ Sex & 4 & 4.97 & 1.46 & 0.217 \\
\hline & Error & 211 & 3.41 & & \\
\hline \multirow[t]{4}{*}{ Flight distance $(\mathrm{km})$} & Rear temperature & 4 & 137.61 & 5.38 & $<$ \\
\hline & & & & & 0.001 \\
\hline & Sex & 1 & 5.25 & 0.21 & 0.651 \\
\hline & Rear temperature $\times$ Sex & 4 & 17.95 & 0.70 & 0.592 \\
\hline
\end{tabular}




\begin{tabular}{llllll}
\hline & Error & 211 & 25.58 & & \\
Average velocity $(\mathrm{km} / \mathrm{h})$ & Rear temperature & 4 & 1.63 & 3.02 & 0.119 \\
& Sex & 1 & 0.07 & 0.13 & 0.721 \\
& Rear temperature $\times$ Sex & 4 & 0.12 & 0.22 & 0.928 \\
& Error & 211 & 0.54 & & \\
\hline
\end{tabular}

Table 3 Flight capacity of $C$. medinalis males and females exposed to different rearing temperatures in the immature stage.

\begin{tabular}{|c|c|c|c|c|c|c|}
\hline \multirow[t]{2}{*}{ Parameters } & \multirow[t]{2}{*}{ Sex } & \multicolumn{5}{|c|}{ Rearing temperatures } \\
\hline & & $18^{\circ} \mathrm{C}$ & $22{ }^{\circ} \mathrm{C}$ & $26^{\circ} \mathrm{C}$ & $30^{\circ} \mathrm{C}$ & $34{ }^{\circ} \mathrm{C}$ \\
\hline \multirow[t]{2}{*}{ Flight duration (h) } & Female & $2.34 \pm 0.47 \mathrm{ab}$ & $3.37 \pm 0.36 \mathrm{ab}$ & $3.87 \pm 0.37 \mathrm{a}$ & $2.15 \pm 0.42 b$ & $3.25 \pm 0.36 \mathrm{ab}^{*}$ \\
\hline & Male & $3.09 \pm 0.55 \mathrm{ab}$ & $3.04 \pm 0.34 \mathrm{ab}$ & $3.74 \pm 0.34 \mathrm{a}$ & $1.86 \pm 0.43 b$ & $2.02 \pm 0.34 \mathrm{~b}$ \\
\hline \multirow[t]{2}{*}{ Flight distance $(\mathrm{km})$} & Female & $4.42 \pm 1.14 \mathrm{ab}$ & $7.13 \pm 1.09 \mathrm{ab}$ & $8.12 \pm 1.13 \mathrm{a}$ & $2.78 \pm 0.55 b$ & $6.30 \pm 0.98 \mathrm{ab}$ \\
\hline & Male & $6.07 \pm 1.29 \mathrm{ab}$ & $6.34 \pm 0.96 \mathrm{ab}$ & $7.92 \pm 0.97 \mathrm{a}$ & $2.62 \pm 0.74 b$ & $4.15 \pm 0.91 b$ \\
\hline \multirow[t]{2}{*}{ Average velocity $(\mathrm{km} / \mathrm{h})$} & Female & $1.54 \pm 0.21 \mathrm{a}$ & $2.24 \pm 0.17 \mathrm{a}$ & $2.24 \pm 0.14 \mathrm{a}$ & $2.63 \pm 0.13 \mathrm{a}$ & $2.76 \pm 0.18 \mathrm{a}$ \\
\hline & Male & $1.75 \pm 0.21 \mathrm{a}$ & $1.82 \pm 0.15 \mathrm{a}$ & $1.92 \pm 0.13 \mathrm{a}$ & $1.22 \pm 0.13 \mathrm{a}$ & $1.67 \pm 0.14 \mathrm{a}$ \\
\hline
\end{tabular}

Different lowercase letters in the same row indicate significant differences by Tukey's HSD test at $5 \%$ level. "**, " "**" represent significant or highly significant differences in the same column by t-test $(p<0.05$ or $p<0.01)$. Sample sizes, from low to high temperature treatment, are $14,28,29,14$ and 26 females, and 14, 30, 28, 15 and 29 males, respectively.

Table 4 Results of two-way ANOVA of rear temperature and flight treatments (flying vs. non-flying) on oviposition parameters of C. medinalis.

\begin{tabular}{llllll}
\hline Parameters & Source & Df & MS & $\boldsymbol{F}$ & $\boldsymbol{P}$ \\
\hline Preoviposition period (d) & Flight & 1 & 0.18 & 0.02 & 0.881 \\
& Rear temperature & 4 & 25.95 & 3.21 & 0.014 \\
& Flight $\times$ rear temperature & 4 & 47.55 & 5.88 & $<0.001$ \\
& Error & 239 & 8.09 & & \\
Period of first oviposition (d) & Flight & 1 & 60.21 & 7.44 & 0.007
\end{tabular}




\begin{tabular}{|c|c|c|c|c|c|}
\hline & Rear temperature & 4 & 1.80 & 0.22 & 0.926 \\
\hline & Flight $\times$ rear temperature & 4 & 44.54 & 5.50 & $<0.001$ \\
\hline & Error & 239 & 8.09 & & \\
\hline \multirow[t]{4}{*}{ Lifetime fecundity } & Flight & 1 & 239587.29 & 25.23 & $<0.001$ \\
\hline & Rear temperature & 4 & 78574.77 & 8.28 & $<0.001$ \\
\hline & Flight $\times$ rear temperature & 4 & 38170.91 & 4.02 & 0.004 \\
\hline & Error & 239 & 9495.81 & & \\
\hline \multirow[t]{4}{*}{ Mating frequency } & Flight & 1 & 3.18 & 9.39 & 0.002 \\
\hline & Rear temperature & 4 & 1.05 & 3.10 & 0.016 \\
\hline & Flight $\times$ rear temperature & 4 & 0.99 & 2.93 & 0.022 \\
\hline & Error & 239 & 0.34 & & \\
\hline \multirow[t]{4}{*}{ Female longevity (d) } & Flight & 1 & 121.79 & 5.82 & 0.017 \\
\hline & Rear temperature & 4 & 239.13 & 11.43 & $<0.001$ \\
\hline & Flight $\times$ rear temperature & 4 & 70.42 & 3.37 & 0.011 \\
\hline & Error & 239 & 20.93 & & \\
\hline \multirow[t]{4}{*}{ Oviposition period (d) } & Flight & 1 & 81.24 & 5.23 & 0.023 \\
\hline & Rear temperature & 4 & 137.87 & 8.88 & $<0.001$ \\
\hline & Flight $\times$ rear temperature & 4 & 36.10 & 2.33 & 0.057 \\
\hline & Error & 239 & 15.52 & & \\
\hline \multirow[t]{4}{*}{ Mating rate } & Flight & 1 & 1.08 & 4.48 & 0.035 \\
\hline & Rear temperature & 4 & 0.41 & 1.70 & 0.152 \\
\hline & Flight $\times$ rear temperature & 4 & 0.23 & 0.950 & 0.437 \\
\hline & Error & 239 & 0.24 & & \\
\hline
\end{tabular}

Table 5 Reproductive performance of $C$. medinalis females between the flying and non-flying groups treated by different rearing temperatures in the immature stage.

\begin{tabular}{|c|c|c|c|c|c|c|}
\hline \multirow[t]{2}{*}{ Parameters } & \multirow[t]{2}{*}{ Treatments } & \multicolumn{5}{|c|}{ Rearing temperatures } \\
\hline & & $18^{\circ} \mathrm{C}$ & $22{ }^{\circ} \mathrm{C}$ & $26^{\circ} \mathrm{C}$ & $30^{\circ} \mathrm{C}$ & $34^{\circ} \mathrm{C}$ \\
\hline Lifetime fecundity & Flying & $94.75 \pm 16.34 \mathrm{a}^{* *}$ & $46.16 \pm 10.48 \mathrm{ab}^{* *}$ & $78.30 \pm 17.70 \mathrm{ab}$ & $48.00 \pm 23.00 \mathrm{ab}$ & $30.35 \pm 8.61 \mathrm{~b}$ \\
\hline
\end{tabular}




\begin{tabular}{|c|c|c|c|c|c|c|}
\hline \multirow[t]{2}{*}{ Mating frequency } & Flying & $0.33 \pm 0.10 \mathrm{a}^{* *}$ & $0.44 \pm 0.10 \mathrm{a}^{*}$ & $0.48 \pm 0.11 \mathrm{a}$ & $0.33 \pm 0.17 \mathrm{a}$ & $0.30 \pm 0.10 \mathrm{a}$ \\
\hline & Nonflying & $1.05 \pm 0.20 \mathrm{a}$ & $0.81 \pm 0.10 \mathrm{ab}$ & $0.51 \pm 0.08 \mathrm{bc}$ & $0.32 \pm 0.10 \mathrm{c}$ & $0.42 \pm 0.10 \mathrm{bc}$ \\
\hline Female longevity (d) & Flying & $15.21 \pm 1.07 \mathrm{a}$ & $9.44 \pm 0.89 \mathrm{~b}^{* *}$ & $11.96 \pm 1.05 \mathrm{ab}^{* *}$ & $13.33 \pm 1.59 \mathrm{ab}$ & $9.13 \pm 0.55 b$ \\
\hline \multirow[t]{2}{*}{ Oviposition period (d) } & Flying & $7.92 \pm 0.75 \mathrm{a}$ & $3.72 \pm 0.63 \mathrm{~b}^{* *}$ & $5.56 \pm 0.95 \mathrm{ab}$ & $3.67 \pm 1.33 \mathrm{~b}$ & $3.26 \pm 0.44 b$ \\
\hline & Nonflying & $8.05 \pm 0.98 \mathrm{a}$ & $7.76 \pm 0.72 \mathrm{a}$ & $6.74 \pm 0.79 \mathrm{ab}$ & $3.68 \pm 0.64 \mathrm{c}$ & $4.04 \pm 0.63 \mathrm{bc}$ \\
\hline
\end{tabular}

Different lowercase letters in the same row indicate significant differences by Tukey's HSD test at $5 \%$ level. " $*$ ", “**” represent significant or highly significant differences in the same column by t-test $(p<0.05$ or $p<0.01)$. Sample sizes for each flying treatment are 22, 42, 35, 22 and 24 females, and each control treatment are 24, 25, 23, 15 and 23 females, from left to right, respectively.

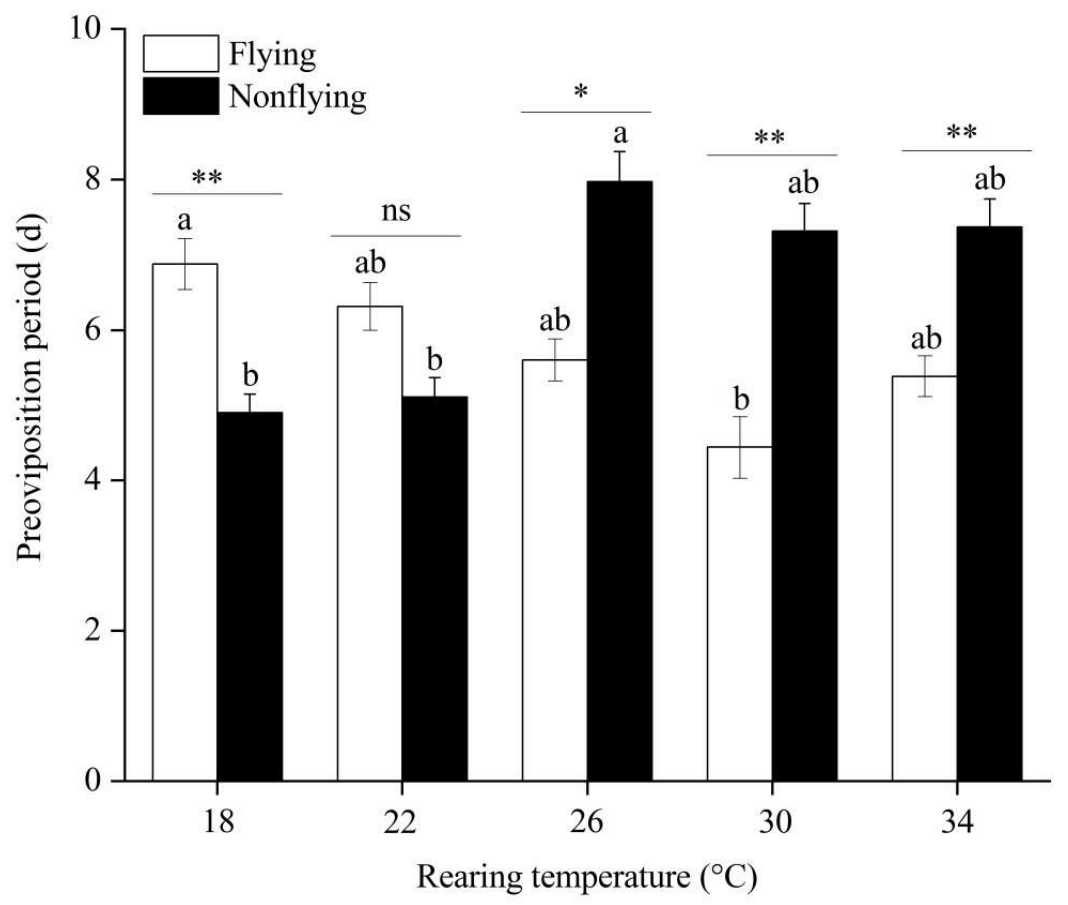

Figure 1. Preoviposition period (POP) of C. medinalis in the flying vs. non-flying groups under different rearing temperatures. Data are presented as mean \pm SE. Different lowercase letters indicate significant differences by Tukey's HSD test at $5 \%$ level. " “*”, “**” represent significant or highly significant differences in the same bars by t-test $(p<0.05$ or $p<0.01)$. Sample sizes for each flying treatment are 22, 42, 35, 22 and 24 females, and each control treatment are 24, 25, 23, 15 and 23 females, from low to high temperature, respectively. 


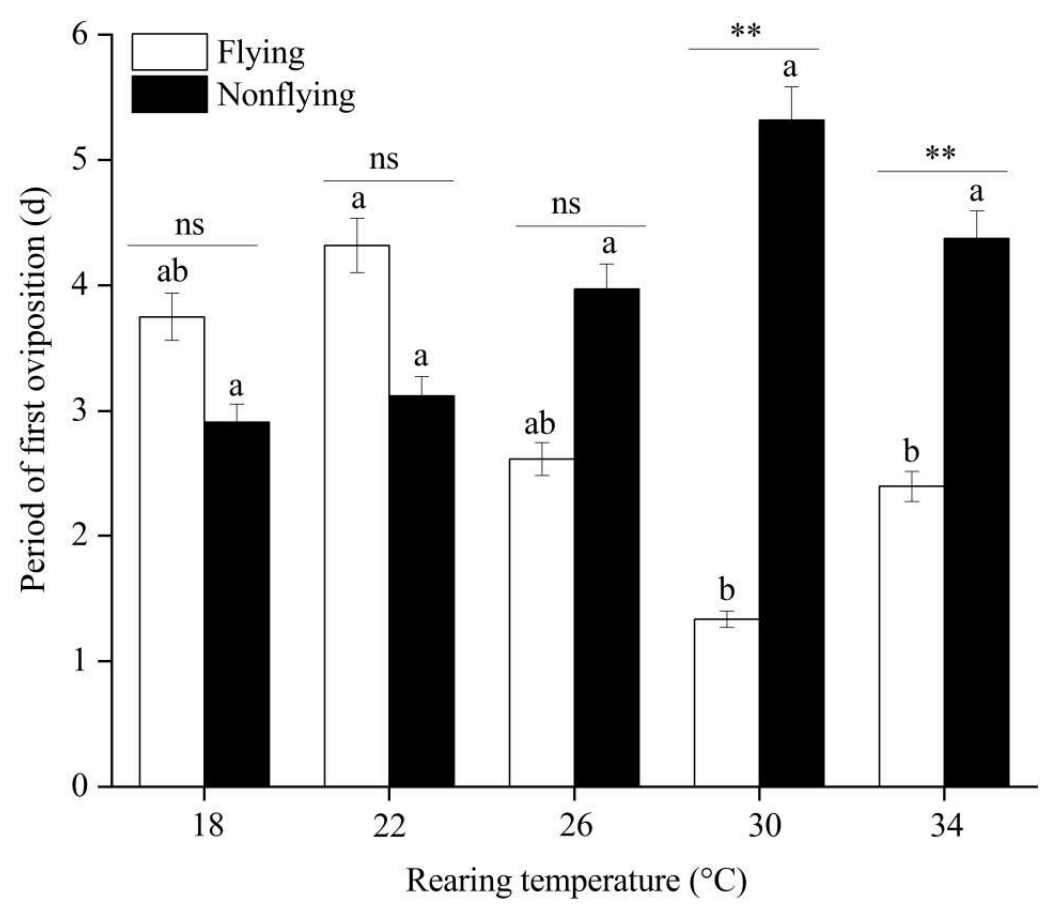

Figure 2. Period of first oviposition (PFO) of $C$. medinalis in the flying vs. non-flying groups under different rearing temperatures. Different lowercase letters above group bars indicate significant differences by Tukey's HSD tests $(p<0.05)$. * ** above bars represent significant or highly significant differences between the flying and non-flying treatments at the same temperature (t-test, $p<0.05$ or $p<0.01$ ). Sample sizes, from low to high temperature, in flying treatments are 22,42 , 35,22 and 24 females, and in control treatments are 24, 25, 23, 15 and 23 females, respectively.

\section{Discussion}

Temperature is considered one major environmental factor as it could profoundly influence the population development and reproduction as well as subsequent migratory capacity and behavior of migratory insects [41-43]. In this study, we found that below or above the optimal rearing temperatures in the immature stage (including egg, larval, or pupal stages) negatively affected the larval development and subsequent adult reproduction and flight capacity of $C$. medinalis, which were consistent with previous findings $[10,44]$. Low rearing temperatures $\left(18\right.$ and $\left.22{ }^{\circ} \mathrm{C}\right)$ significantly delayed the larval development, but accelerated adult reproduction compared to the $26{ }^{\circ} \mathrm{C}$ treatment. However, high rearing temperatures $\left(30\right.$ and $34^{\circ} \mathrm{C}$ ) accelerated the development of larva and pupa, but caused the delay of adult oviposition and the decrease of egg production. Furthermore, flight also significantly affected the reproduction of adult from different rearing temperature treatments. Flight favored the migration of $C$. medinalis adults after experiencing high rearing temperatures $\left(30\right.$ and $34{ }^{\circ} \mathrm{C}$ ), via shortening the preoviposition period and increasing the synchronized oviposition. On contrast, flight significantly promoted the lifetime fecundity and mating frequency of moths treated by low rearing temperatures $\left(18\right.$ and $22{ }^{\circ} \mathrm{C}$ ), thereby reducing the motivation of migration. These results may reflect adaptive ecological strategies to different environmental temperatures for $C$. medinalis.

Development of C. medinalis differed significantly under different un-mature rearing temperatures. Both high and low temperatures (above $26^{\circ} \mathrm{C}$ ) caused higher larval and pupal mortality, and lower pupation and eclosion rate. On contrast, C. medinalis larvae 
and pupae developed well at normal temperature $26^{\circ} \mathrm{C}$, with the lowest mortality and the highest pupation rate and eclosion rate. Thus, these results were consistent with previous reports that extreme low and high temperatures negatively influenced the larval growth and development [45-46], such as Spodoptera exigua (Hübner) [47], M. separata (Walker) [13] and other Lepidopteran insect species. As expected, low temperature resulted in slower growth rate and longer development time in insects [48], while high temperature accelerated the development of the egg, larval and pupal period [40]. Our results also found that low rearing temperatures (18 and $\left.22{ }^{\circ} \mathrm{C}\right)$ significantly slowed down the larval development and caused poor synchronized eclosion of C. medinalis, with significant increases in larval and pupal period as well as the lengthening of the period of synchronized eclosion compared to $26^{\circ} \mathrm{C}$. However, high rearing temperatures $\left(30\right.$ and $34^{\circ} \mathrm{C}$ ) reduced the larval and pupal period, but accelerated maturation processes.

Reproductive traits are sensitive to thermal variations, but the effect of stressful temperatures in early life stages on adult performance is still a matter of debate in insects [17]. Potter et al. [49] stated that early life stress had no effect on adult performance based on the adaptive decoupling hypothesis and life cycle modularity hypothesis. However, recent studies have found that extreme high temperatures occurring in immature stage (including egg, larval, or pupal stages) can decrease the fecundity of adults through carry-over effects [50-51] or even reduce the offspring survival via transgenerational effects [52]. Our results showed that high rearing temperatures $\left(30\right.$ and $\left.34^{\circ} \mathrm{C}\right)$ in immature stage negatively affected the reproduction and longevity of adults. However, low rearing temperatures in early life stages positively stimulated adult reproduction, which resulted in decreased POP and increased egg production of females. These findings suggested that rearing temperature in the immature stage can influence reproductive performance of C. medinalis adults. In many migratory insect species, relatively long POP was an important behavioral characteristic of migrants [19, 23, 39], which might reduce the number of days available for reproduction but result in increased flight potential and time window to engage in migration [43], such as Loxostege sticticalis (L.) [53], M. separata (Walker) [54] and C. medinalis (Guenée) [55]. We therefore speculated that rearing temperatures in the immature stage might determine the migration and differentiation of $C$. medinalis adults. Our results were consistent with the previous findings that rearing temperature in the immature stage could induce development into either resident or migrant adults for M. separata [33, 37]. Females at low un-mature rearing temperature had a greater resident propensity with strong reproductive ability [56]. On contrast, high un-mature rearing temperature increased their migratory propensity and motivation [11]. Field studies also indicated that the primary driver of $C$. medinalis northward migration over the summer months was typically assumed to escape from high temperature [31].

Temperature can directly influence flight like other insect behaviors by physiological regulations [57-59]. Below or above the optimal threshold temperature negatively affects the flight performance of migratory insects [60], such as M. separata (Walker) [11], Mythimna loreyi (Walker) [40], and Bactrocera dorsalis (Hendel) [59]. Similar results were obtained in our study with the treatments below or above $26^{\circ} \mathrm{C}$ in the immature stage reducing the flight duration and flight distance of $C$. medinalis adults. The reason for the negative effect may be closely related with the activity of metabolic rate and flight muscle power output regulated by temperature [61]. Below the optimal temperature, an insect reduces the locomotor activities of flight muscles which should be provided energy during flight as a consequence of lower metabolic rate [62]. High temperatures cause the inactivation of its nervous system due to increasing heat production by flight muscles above the upper critical thermal limit [63].

Interestingly, female moths have stronger flight propensity than males in some species [64], which undertake the task of finding food and oviposition sites [65]. Guo et al. [36] reported that female $C$. medinalis had a greater migratory propensity and flight capability than males at constant $26^{\circ} \mathrm{C}$ in a laboratory population. Similar patterns were observed in M. separata [66] and Culex pipiens pallens [67]. However, differential flight 
performances between the sexes in response to rearing temperatures in the immature stage are less common in migratory insects. In this study, we further found that flight performances of $C$. medinalis females and males largely depended on rearing temperatures. Females exhibited better flight performance than males at above $18{ }^{\circ} \mathrm{C}$, with greater flight duration, distance and velocity. On contrast, $18{ }^{\circ} \mathrm{C}$ caused poorer flight performance of females than males.

Generally, migration is an energy-intensive activity, along with worse environments, new enemies and increased risk of mortality [19, 22]. Migration-mediated reproductive costs are not absolutely negative, and differ from species to species and the flight stage in some migratory insects $[37,68]$. Previous studies have demonstrated that insects can choose an appropriate take-off time or migration stage to weaken the oogenesis-flight syndrome and therefore pay no reproductive costs for their migration [25, 37]. Zhang et al. [24] reported that flight on the first day after emergence significantly promoted the reproduction of $C$. medinalis under laboratory conditions. Our study further revealed that the effects of flight on reproduction of $C$. medinalis on the first day after emergence were also mediated by rearing temperatures in the immature stage. Compared to control females, flying females after experiencing low rearing temperature treatments (18 and 22 ${ }^{\circ} \mathrm{C}$ ) started laying eggs at a later age and had lower total fecundity and mating frequency. These results suggested that low rearing temperatures negatively affected the migration at the expense of huge reproductive costs, probably because larvae which experienced low temperature were conducive to develop into residents. Supporting evidence for this comes from previous studies of the reproductive benefits of low temperature in $M$. separata $[11,33,56]$. However, high rearing temperatures of 30 and $34{ }^{\circ} \mathrm{C}$ significantly decreased the POP and increased the synchrony of egg-laying of flying females with a significant decrease in PFO, causing an increase of subsequent larval densities and even population outbreaks. A similar effect has been observed in Loxostege sticticalis [39]. Combined with decreased reproductive performance and enhanced migratory propensity of $C$. medinalis treated with high rearing temperatures, we therefore supposed that high rearing temperatures $\left(30\right.$ and $34^{\circ} \mathrm{C}$ ) were most likely to trigger the onset of migration of $C$. medinalis adults for survival, which was consistent with the main motivation of insect migration triggered as a response to external environmental factors [22].

\section{Conclusions}

Taken together, our data indicate that $C$. medinalis can choose different adaptive strategies to help buffer the impacts of unsuitable temperatures. When rearing temperature in the immature stage surpasses the optimum for reproduction, $C$. medinalis accelerates maturation development and tends to invest more energy in migration to improve survival, generating the costs of delayed reproduction processes and reduced reproduction output. However, rearing temperature below the optimum for reproduction, $C$. medinalis delays maturation development but can also accelerate reproduction processes and stimulate adult reproduction. These findings enhance our understanding of diverse adaptive strategies in response to different temperatures in insects and provide valuable information for C. medinalis pest management.

Author Contributions: Conceptualization, W.X.L. and L.Z.; methodology, W.X.L., X.J.C. and L.Z.; software, W.X.L. and X.J.C.; formal analysis, W.X.L., X.J.C. and L.Z.; writing-original draft preparation, W.X.L.; data curation, X.F.J., Y.X.C., J.X.X. and L.Z.; writing-review and editing, W.X.L. and L.Z.; project administration, X.F.J.,Y.X.C., J.X.X. and L.Z.; funding acquisition, X.F.J. and L.Z.; All authors have read and agreed to the published version of the manuscript.

Funding: This research was supported by the National Natural Science of China (31871951), the Chemical Fertilizer and Pesticide Reduction and Synergism Research Project of China (2017YFD0201802, 2017YFD0201701), the National Natural Science of Beijing (6172030), the China Agriculture Research System-Green-Manure (CARS-22) and the Fundamental Research Funds of China West Normal University (Project No. 412/412834).

Institutional Review Board Statement: Not applicable. 
Data Availability Statement: The data presented in this study are available on request from the corresponding author

Acknowledgments: We thank Xing-Cheng Xie from Chinese Academy of Agricultural Sciences for his advice and suggestions and the three anonymous reviewers for making suggestions that greatly improved the paper.

Conflicts of Interest: The authors declare no conflict of interest.

\section{References}

1. Angilletta Jr, M.J. Thermal adaptation: a theoretical and empirical synthesis. Oxford University Press, Oxford, UK, 2009.

2. Fischer, K.; Kolzow, N.; Holtje, H.; Karl, I. Assay conditions in laboratory experiments: is the use of constant rather than fluctuating temperatures justified when investigating temperature-induced plasticity? Oecologia. 2011, 166, $23-33$.

3. Piyaphongkul, J.; Pritchard, J.; Bale, J. Heat stress impedes development and lowers fecundity of the brown planthopper Nilaparvata lugens (Stl). PLoS One. 2012, 7, e47413.

4. Pineda, A.; Dicke, M.; Pieterse, C.M.J.; Pozo, M.J. Beneficial microbes in a changing environment: are they always helping plants to deal with insects? Func. Ecol. 2013, 27, 574-586.

5. Mironidis, G.K. Development, survivorship and reproduction of Helicoverpa armigera (Lepidoptera: Noctuidae) under fluctuating temperatures. Bull. Entomolog. Res. 2014, 104, 751-764.

6. Kingsolver, J.G.; Higgins, J.K.; Augustine, K.E. Fluctuating temperatures and ectotherm growth: distinguishing non-linear and time-dependent effects. J. Exp. Biol. 2015, 218, 2218-2225.

7. Qin, J.Y.; Liu, Y.Q.; Zhang, L.; Cheng, Y.X.; Luo, L.Z.; Jiang, X.F. Effects of temperatures on the development and reproduction of the armyworm, Mythimna roseilinea: Analysis using an age-stage, two-sex life table. J. Integr. Agr. 2018a, 7, $1506-1515$.

8. Zhou, Z.; Guo, J.; Chen, H.; Wan, F. Effects of temperature on survival, development, longevity, and fecundity of Ophraella communa (Coleoptera: Chrysomelidae), a potential biological control agent against Ambrosia artemisiifolia (Asterales: Asteraceae). Environ. Entomol. 2010, 39, 1021-1027.

9. Regniere, J.; Powell, J.; Bentz, B.; Nealis, V. Effects of temperature on development, survival and reproduction of insects: Experimental design, data analysis and modeling. J. Insect Physiol. 2012, 58, 634-647.

10. Qin, J.Y.; Zhang, L.; Liu, Y.Q.; Sappington, T.W.; Cheng, Y.X.; Luo, L.Z.; Jiang, X.F. Population projection and development of the Mythimna loreyi as affected by temperature: Application of an age-stage, two-sex life table. J. Econ Entomol. 2017,110, 15831591.

11. Jiang, X.F.; Luo, L.Z.; Hu, Y. Influence of rearing temperature on flight and reproductive capacity of adult oriental armyworm, Mythimna separata (Walker). Acta Entomol. Sin. 2000, 20, 288-292.

12. Mourier, H.; Poulsen, K.P. Control of insects and mites in grain using a high temperature/short time (HTST) technique. J. Stored. Prod. Res. 2000, 36, 309-318.

13. Li, B.L.; Xu, X.L.; Ji, J.Y.; Wu, J.X. Effects of constant and stage-specific-alternating temperature on the survival, development and reproduction of the oriental armyworm, Mythimna separata (Walker) (Lepidoptera: Noctuidae). J. Integr. Agr. 2018, 7, 15451555.

14. Hill, J.K.; Gatehouse, A.G. Effect of temperature and photoperiod on development and pre-reproductive period of the silver $Y$ moth Autographa gamma (Lepidoptera: Noctuidae). Bull. Entomolog. Res. 1992, 82, 335-341.

15. Han, E.N.; Gatehouse, A. G. Effect of temperature and photoperiod on the calling behaviour of a migratory insect, the oriental armyworm Mythimna separata. Physiol. Entomol. 1991, 16, 419-427.

16. Mirth, C.K.; Saunders, T.E.; Amourda, C. Growing Up in a Changing World: Environmental Regulation of Development in Insects. Annu. Rev. Entomol. 2021, 66, 4.1-4.19.

17. Ma, C.S.; Ma, G.; Pincebourde, S. Survive a Warming Climate: Insect Responses to Extreme High Temperatures. Annu. Rev. Entomol. 2020, 66, 8.1-8.22.

18. Stefanescu, C.; Páramo, F.; Åkesson, S.; Alarcón, M.; Anna, Á.; Brereton, T.; Carnicer, J., Cassar, L. F.; Fox, R.; Heliölä, J. Multi-generational long-distance migration of insects: studying the painted lady butterfly in the Western Palaearctic. Ecography. 2013, 36, 474-486.

19. Rankin, M.A.; Burchsted, J.C.A. The cost of migration in insects. Annu. Rev. Entomol. 1992, 37, 533-559.

20. Sonia, A.; Rebecca, B.; Barbara, A.H. Animal migration and infectious disease risk. Science. 2011, 331, $296-302$.

21. Dingle, H. Migration: The Biology of Life on the Move. 2nd ed. Oxford University Press, New York, 2014.

22. Chapman, J.W.; Reynolds, D.R.; Wilson, K. Long-range seasonal migration in insects: Mechanisms, evolutionary drivers and ecological consequences. Ecol. Lett. 2015, 18, 287-302.

23. Zera, A.J.; Denno, R.F. Physiology and ecology of dispersal polymorphism in insects. Annu. Rev. Entomol. 1997, 42, 207-230.

24. Zhang, L.; Pan, P.; Sappington, T.W.; Lu, W.X.; Luo, L.Z.; Jiang, X.F. Accelerated and synchronized oviposition induced by flight of young females may intensify larval outbreaks of the rice leaf roller. PLoS One. 2015, 10, e0121821.

25. Guerra, P.A.; Pollack, G.S. Flight behavior attenuates the trade-off between flight capability and reproduction in a wing polymorphic cricket. Biol. Lett. 2009, 5, 229-231. 
26. Zhang, Y.; Wu, K.M.; Kris, A.G.W.; George, E.H. Trade-off between flight and fecundity in the soybean aphid (Hemiptera: Aphididae). J. Econ Entomol. 2009, 102, 133-138.

27. Saglam, I.K.; Roff, D.A.; Fairbairn, D.J. Male sand crickets trade-off flight capability for reproductive potential. J. Evolution Biol. 2010, 21, 997-1004.

28. Johnson, C.G. Migration and Dispersal of Insects by Flight. Methuen, London, 1969.

29. Bautista, R.C.; Henirichs, E.A.; Rejesus, R.S. Economic injury levels for the rice leaf folder Cnaphalocrocis medinalis (Lepidoptera: Pyralidae): insect infestation and artificial leaf removal. Environ Entomol. 1984, 13, 439-443.

30. Riley, J.R.; Reynolds, D.R.; Smith, A.D.; Edwards, A.S.; Zhang, X.X.; Cheng, X.N.; Wang, H.K.; Cheng, J.Y.; Zhai, B.P.. Observations of the autumn migration of the rice leaf roller Cnaphalocrocis medinalis (Lepidoptera: Pyralidae) and other moths in eastern China. Bull. Entomol. Res. 1995, 85, 397-414.

31. Zhang, X.X.; Lu, Z.Q.; Geng, J.G.; Li, G.Z.; Chen, X.L.; Wu, X.W. Studies on the migration of rice leaf roller Cnaphalocrocis medinalis (Guenée). Acta Entomol. Sin. 1980, 2, 130-140.

32. Li, G.B.; Wang, H.X.; Hu, W.X. Route of the seasonal migration of the oriental armyworm moth in the eastern part of China as indicated by a three-year result of releasing and recapturing of marked moths. Acta Phytopathol Sin. 1964, 3,101-110.

33. Jiang, X.F.; Luo, L.Z.; Zhang, L.; Sappington, T.W.; Hu, Y. Regulation of migration in Mythimna separata (Walker) in China: a review integrating environmental, physiological, hormonal, genetic, and molecular factors. Environ. Entomol. 2011, 40, $516-533$.

34. Wang, F.; Yang, Y.F.; Lu, M.H.; Luo, S.Y.; Zhai, B.P.; Lim. K.S. Determining the migration duration of rice leaf folder (cnaphalocrocis medinalis (guenée)) moths using a trajectory analytical approach. Sci. Rep. 2017, 7, 39853.

35. Guo, J.W.; Li, W.P.; Zhang, J.; Liu, X.D.; Zhai, B.P.; Gao. H. Cnaphalocrocis medinalis moths decide to migrate when suffering nutrient shortage on the first day after emergence. Insects. 2019a, 10, 364.

36. Guo, J.W.; Yang, F.; Li, P.; Liu, X.D.; Zhai, B.P. Female bias in an immigratory population of cnaphalocrocis medinalis moths based on field surveys and laboratory tests. Sci. Rep. 2019b, 9, 18388.

37. Jiang, X.F.; Luo, L.Z.; Sappington, T.W. Relationship of flight and reproduction in beet armyworm, Spodoptera exigua (Lepidoptera: Noctuidae), a migrant lacking the oogenesis-flight syndrome. J. Insect Physiol. 2010, 56, 1631-1637.

38. Zhang, L.; Cheng, L. L.; Chapman, J.W.; Sappington, T.W.; Liu, J.J.; Cheng, Y.X.; Jiang, X.F. Juvenile hormone regulates the shift from migrants to residents in adult oriental armyworm, Mythimna separata. Sci. Rep. 2020, 10, 11626.

39. Cheng, Y.X.; Luo, L.Z.; Jiang, X.F.; Sappington, T.W. Synchronized oviposition triggered by migratory flight intensifies larval outbreaks of beet webworm. PLoS One. 2012, 7, e31562.

40. Qin, J.Y.; Liu, Y.Q.; Zhang, L.; Cheng, Y.X.; Sappington, T.W.; Jiang, X.F. Effects of moth age and rearing temperature on the flight performance of the loreyi leafworm, Mythimna loreyi (Lepidoptera: Noctuidae), in tethered and free flight. J. Econ Entomol. 2018b, 111, $1243-1248$

41. Chown, S.L.; Gaston, K.J. Body size variation in insects: a macro ecological perspective. Biol. Rev. 2010, 85, $139-169$.

42. Sinclair, B.J.; Williams, C.M.; Terblanche, J.S. Variation in thermal performance among insect populations. Physiol. Biochem. Zool. 2012, 85, 594-606.

43. Cheng, Y.X.; Wang, K.; Sappington, T.W.; Luo, L.Z.; Jiang, X.F. Response of reproductive traits and longevity of beet webworm to temperature, and implications for migration. J. Insect. Sci. 2015, 15, 154.

44. Jiang, X.F. Regularity of population occurrence and migration in the oriental armyworm, Mythimna separata (Walker). J. Integr. Agr. 2018, 17, 1482-1505.

45. Mironidis, G.K.; Savopoulou-Soultani, M. Development, survivorship, and reproduction of Helicoverpa armigera (Lepidoptera: Noctuidae) under constant and alternating temperatures. Environ. Entomol. 2008, 37, $16-28$.

46. Ghazanfar, M.U.; Hagenbucher, S.; Romeis, J.; Grabenweger, G.; Meissle, M. Fluctuating temperatures influence the susceptibility of pest insects to biological control agents. J. Pest Sci. 2020, 93, 1007-1018.

47. Karimi-Malati, A.; Fathipour. Y.; Talebi, A.A.; Bazoubandi. M. Lifetable parameters and survivorship of Spodoptera exigua (Lepidoptera: Noctuidae) at constant temperatures. Environ. Entomol. 2014, 43, 795-803.

48. Sibly, R.M.; Atkinson, D. How rearing temperature affects optimal adult size in ectotherms. Func. Ecol. 1994, 8, $486-93$.

49. Potter, K.A.; Woods, A.; Pincebourde, S. Microclimatic challenges in global change biology. Global. Change. Biol. 2013, 19, $2932-39$.

50. Klockmann, M.; Günter, F.; Fischer, K. Heat resistance throughout ontogeny: Body size constrains thermal tolerance. Global. Change. Biol. 2017, 23, 686-96.

51. Chen, B.; Feder, M.E.; Kang, L. Evolution of heat-shock protein expression underlying adaptive responses to environmental stress. Mol. Ecol. 2018, 27, 3040-54.

52. Liang, L.N.; Zhang, W.; Ma, G.; Hoffmann, A.; Ma, C.S. A single hot event stimulates adult performance but reduces egg survival in the oriental fruit moth, Grapholitha molesta. PLoS One. 2014, 9, e116339.

53. Kong, H. L.; Luo, L.Z.; Jiang, X.F.; Zhang, L. Effects of larval density on flight potential of the beet webworm, Loxostege sticticalis (Lepidoptera: Pyralidae). Environ. Entomol. 2010, 39, 1579-1585.

54. Jiang, X.F.; Luo, L.Z. Comparison of behavioral and physiological characteristics between the emigrant and immigrant populations of the oriental armyworm, Mythimna separata (Walker). Acta Entomol. Sin. 2005, 48, 61-67.

55. Wang, F.Y.; Zhang, X.X.; Zhai, B.P. Flight and re-migration capacity of the rice leaf folder moth, Cnaphalocrocis medinalis(Guenée) (Lepidoptera: Crambidae). Acta Entomol. Sin. 2010, 53, 1265-1272.

56. Zhang, L.; Jiang, X.F.; Luo, L.Z. Determination of sensitive stage for switching migrant oriental armyworms into residents. Environ. Entomol. 2008, 37, 1389-1395.

57. Taylor, L.R. Analysis of the effect of temperature on insects in flight. J. Anim Ecol. 1963, 32, 99-117.

58. Stevenson, R.D.; Josephson, R.K. Effects of operating frequency and temperature on mechanical power output from moth flight muscle. $J$. Exp. Biol. 1990, 149, 61-78.

59. Makumbe, L.M.; Moropa, T.P.; Manrakhan, M.; Weldon, C.W. Effect of sex, age and morphological traits on tethered flight of Bactrocera dorsalis (Hendel) (Diptera:Tephritidae) at different temperatures. Physiol. Entomol. 2020, 7, 110-119.

60. Goller, F.; Esch, H. Comparative study of chill-coma temperatures and muscle potentials in insect flight muscles. J. Exp. Biol. 1990, 150, $221-231$.

61. Bale, J. S. Insects and low temperatures: from molecular biology to distributions and abundance. Philos. T. R. Soc. B. 2002, 357, 849-862. 
62. MacMillan, H.A.; Sinclair, B.J. Mechanisms underlying insect chill-coma. J. Insect Physiol. 2011, 57, 12-20.

63. Neven, L.G. Physiological responses of insects to heat. Postharvest. Biol Tec. 2000, 21, 103-111.

64. Davis, M.A. The flight and migration ecology of the red milkweed beetle (Tetraopes Tetraophthalmus). Ecology. 1984, 65, $230-234$.

65. Martínez, A.S.; Villacide, J.; Fernández Ajó, A.A.S.; Martinson, J.; Corley, J.C. Sirex noctilio flight behavior: toward improving current monitoring techniques. Entomol. Exp. Appl. 2014, 152, 135-14.

66. Luo, L.Z.; Jiang, X.F.; Li, K.B.; Hu, Y. Influences of flight on reproduction and longevity of the oriental armyworm, Mythimna separata (Walker). Acta Entomol. Sin. 1999, 2, 150-158.

67. Cui, J.; Li, S.; Zhao, P.; Zou, F. Flight capacity of adult Culex pipiens pallens (Diptera: Culicidae) in relation to gender and day-age. J. Med. Entomol. 2013, 50, 1055-1058.

68. Sappington, T.W.; Showers, W. Reproductive maturity, mating status, and long-duration flight behavior of Agrotis ipsilon and the conceptual misuse of the oo-genesis flight syndrome by entomologists. Environ. Entomol. 1992, 21, 677-688. 